\title{
The guardians of metrology
}

\author{
The establishment of a global metric system of units as agreed upon in the Metre Convention relies on international \\ as well as national institutes and organizations, of which Stefanie Reichert gives an overview.
}

$\mathrm{n}$ a world where more and more goods are imported, it is important to ensure that specifications - from size and weight to output voltage - can be reliably compared between countries. In other words, "global economies need global metrology" ${ }^{\text {. The }}$ foundation for such a global system of units dates back to the Metre Convention ${ }^{2}$. Signed in 1875 by representatives of 17 nations, who committed to ensure the international unification and improvement of the metric system, it still forms the basis international agreement on units of measurements and now involves 63 member states and 39 associate states and economies.

The Metre Convention established one of the first international organizations, the International Bureau of Weights and Measures $(\mathrm{BIPM})^{3}$. It operates under the direction and supervision of an executive board called the International Committee for Weights and Measures (CIPM), which has 18 members of different nationalities. It is supported by the work of 10 Consultative Committees that bring together experts from all over the world to focus on specialized topics such as photometry and radiometry or ionizing radiation. The members of the CIPM are appointed by, and its work is overseen by, the General Conference on Weights and Measures (CGPM), which every four years organizes a congress, bringing together delegates from all member states and associate states.

The BIPM is now best known for its work to provide the technical basis for the International System of Units, the SI. It also calculates and distributes the international reference time scale UTC, which we all rely on when scheduling meetings with colleagues based in different parts of the world.

Whilst the BIPM focuses on what is now called scientific metrology, there are other international organizations that are responsible for different matters of metrology. The International Organization of Legal Metrology (OIML) was founded in 1955 "to resolve internationally the technical and administrative problems raised by the use of measuring instruments" 4 . For example, it deals with the application of legal requirements to measuring devices and to measurements themselves. This affects many

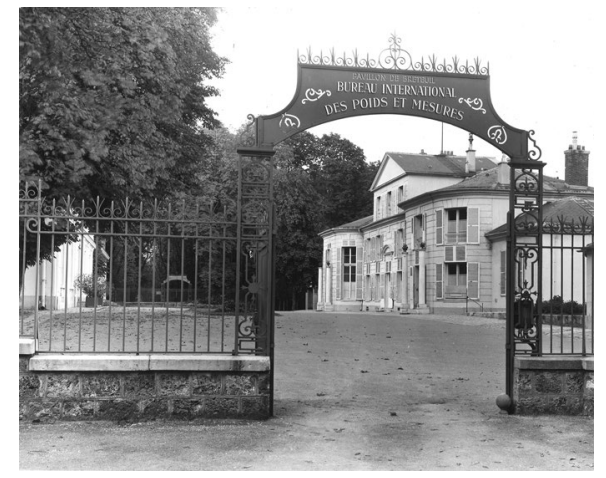

Credit: image courtesy of the BIPM

aspects of legislation from utility meters for measuring the amount of electricity or water we use at home to the packaging sizes of flour or rice sold in supermarkets.

In addition to the OIML, the work of the BIPM is complemented by the International Laboratory Accreditation Cooperation (ILAC). Among other things, this organization is responsible for the accreditation of inspection bodies and perhaps most importantly at the moment - for calibration and (medical) testing laboratories, including specifications for the accreditation of the different testing procedures to detect the SARS-CoV-2 virus in human, animal or sewage samples.

These different organizations work closely together "to promote a world-wide metrology system for industry, commerce, science

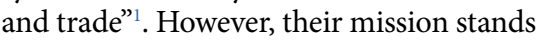
and falls with national efforts, in particular the technical infrastructure required to obtain accurate and reliable measurements. This infrastructure commonly includes facilities for defining standards for the units of measurement - including their further development for future needs - or calibration and testing, in particular for industry. The majority of these tasks falls within the remit of national metrology institutes and designated institutes.

Their tasks are manifold, including the national realization, maintenance and dissemination of SI units and scales to laboratories and users - be it scientific, industrial or commercial.
For example, many national metrology institutes disseminate the official time in their countries. In addition to scientific metrology, national metrology institutes provide services for industry, such as calibration or consultancy, and they also play a crucial role in training through both knowledge and technology transfer, shaping the next generation of metrologists.

In a truly global metrological system, measurements carried out by different national metrology institutes must be comparable. Mutual trust and the recognition of measurement and calibration services rest on three pillars: common guidelines for the practical realization of units, on-site visits by peer reviewers and comparisons of national measurement standards and calibration results. These comparisons are often embedded in regional metrology organizations, such as EURAMET in Europe or the intra-Africa metrology system AFRIMETS that foster regional collaboration between different metrology institutes and bodies.

Through a series of comparisons that each contribute to the uncertainty, a measurement result can be related to a national or international reference - a principle known as metrological traceability. National-scale realizations that are not primary realizations of the SI must be traceable to either the BIPM directly or to the national standards of another country, which is regulated through traceability arrangements.

Together with nationally recognized accreditation bodies, national metrology institutes indeed play a crucial role in the global metrology needed for global economies.

\section{Stefanie Reichert ${ }^{\bowtie}$}

Senior Editor, Nature Physics

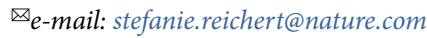

Published online: 14 February 2022 https://doi.org/10.1038/s41567-022-01511-4

\footnotetext{
References

1. EURAMET and the Operation of NMIs: EURAMET Guide No. 1 Version 2.0 (EURAMET, 2015); https://go.nature.com/3rwxwAG 2. Milton, M. J. T. Nat. Phys. 17, 286 (2021)

3. The Metre Convention and Annexed Regulations (BIPM, 1991); https://go.nature.com/3Kn $4 \mathrm{PPh}$

4. Convention Establishing an International Organisation of Legal Metrology (OILM, 2000); https://go.nature.com/3GGl2wO
}

$\mathrm{m} e \mathrm{~s} \mathrm{u} R E_{\mathrm{h}}$

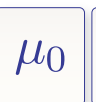

\section{$\varepsilon_{0}$

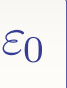

$\sigma$

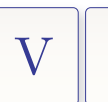

$\mathrm{R}$ e 